\title{
The value of wild pollination ecosystem services to crop production: What does gender of the smallholder farmer got to do with it?
}

\author{
Byela Tibesigwa ${ }^{1}$ \\ ${ }^{1}$ Environment for Development (EfD)
}

May 11, 2020

\begin{abstract}
"Men's crops" and "women's crops" suggest that men and women smallholder farmers in sub-Saharan Africa grow different crops. Yet, this gender division of crops is not considered in the valuation of wild pollinators to crop productivity, and therefore remains unknown, despite considerable coverage of wild pollination ecosystem services. We link a nationally representative panel survey of over 10,000 actual plots managed by male and female farmers; with spatially and temporally land cover maps; together with robust fixed-effects production function methods. We find evidence of gendered-crops and variation in pollination dependency in male- and female-managed farms. Furthermore, statistically significant fixed-effects estimates produce an exponential function which shows that proximity to wild pollinators' natural habits - forests - is important, and that at shorter distances female-managed farms benefit four times more than male-managed farms, and this tapers off as distance increases producing convergence in benefits. We are able to conclude that conservation that preserves the natural habitants of wild pollinators will enhance crop yield especially among female-managed farms. This demonstrates the importance of gender in ecosystem services and suggests that to fully understand their benefits, gender needs to be incorporated into natural capital and sustainable development policies governing smallholder agriculture rich regions.
\end{abstract}

\section{Hosted file}

Manuscript.pdf available at https://authorea.com/users/320538/articles/450055-the-valueof-wild-pollination-ecosystem-services-to-crop-production-what-does-gender-of-thesmallholder-farmer-got-to-do-with-it 